\title{
Gas Phase Oxidation of Toluene and Ethyl Acetate over Proton and Cobalt Exchanged ZSM-5 Nano Catalysts- Experimental Study and ANN Modeling
}

\author{
Seyed Ali Hosseini, Aligholi Niaei, ${ }^{*}$ Dariush Salari, and Azadeh Jodaei \\ Department of Applied Chemistry, Faculty of Chemistry, University of Tariz, Tabriz, Iran. *E-mail: niaei@yahoo.com \\ Received June 25, 2009, Accepted January 15, 2010
}

\begin{abstract}
Activities of nanostructure HZSM-5 and Co-ZSM-5 catalysts (with different Co-loading) for catalytic conversion of ethyl acetate and toluene were studied. The catalysts were prepared by wet impregnation method and were characterized by XRD, BET, SEM, TEM and ICP-AES techniques. Catalytic studies were carried out inside a U-shaped fixed bed reactor under atmospheric pressure and different temperatures. Toluene showed lower reactivity than ethyl acetate for conversion on Co-ZSM-5 catalysts. The effect of Co loading on conversion was prominent at temperatures below $400{ }^{\circ} \mathrm{C}$ and $450{ }^{\circ} \mathrm{C}$ for ethyl acetate and toluene respectively. In a binary mixture of organic compounds, toluene and ethyl acetate showed an inhibition and promotional behaviors respectively, in which the conversion of toluene was decreased at temperatures above $350{ }^{\circ} \mathrm{C}$. Inhibition effect of water vapor was negligible at temperatures above $400{ }^{\circ} \mathrm{C}$. An artificial neural networks model was developed to predict the conversion efficiency of ethyl acetate on Co-ZSM-5 catalysts based on experimental data. Predicted results showed a good agreement with experimental results. ANN modeling predicted the order of studied variable effects on ethyl acetate conversion, which was as follows: reaction temperature $(50 \%)>$ ethyl acetate inlet concentration $(25.085 \%)>$ content of Co loading $(24.915 \%)$.
\end{abstract}

Key Words: Catalytic oxidation, Cobalt exchanged ZSM-5, Volatile organic compounds, ANN modeling

\section{Introduction}

Increasing environmental awareness promotes the stricter regulation of industrial action. Volatile organic compounds are considered as one of the main air pollutants. Catalytic combustion for controlling volatile organic compounds (VOCs) emissions is a competitive method to solve the environmental problems. In this process, high elimination efficiency can be achieved at relatively low temperature, which resulted in considerable environmental and economic benefits in comparison to the case of the thermal incineration. ${ }^{1,2}$

In recent years, supported transition metal oxides were extensively used in controlling VOCs emissions, and special attention has been paid to these systems as a substitute for noble metal containing catalysts. ${ }^{3}$ On other hand, the materials with high thermal stability, resistance to humidity, high specific surface area and ability to stabilize the metal particles in the porous structure are desired to use as catalyst supports. ${ }^{4}$ The catalytic conversion of ethyl acetate and toluene which are commonly used as solvent in chemical processing and industries have been investigated on catalyst supported alumina and zirconia. ${ }^{5-7}$

Nano catalysts because of having high specific surface show high catalytic performance. Metal oxide catalysts play an essential role in the production of petrochemicals, as well as in energy applications and for environmental protection. Zeolites have been claimed as promising supports to stabilize transition metals with great potential as oxidation catalysts. ${ }^{8}$ The availability of zeolites with several porous structures, different composition and hydrophobicity degree, as well as the possibility to control the acidic properties and location of exchanged cations and high specific surface area (nanostructure) have contributed to increase the advantages of zeolites relative to other traditional support materials. ${ }^{9}$ Some authors have explored the possibility of using transition metal exchanged or impregnated zeolite catalyst for deep oxidation. These results suggest that intrinsic properties of the zeolites, such as their acidity and high specific surface area play a determinant role in the catalyst performance, being observed cases in which the main effect of the metal is the modification of the acidity. ${ }^{10-11}$ ZSM-5 is a type of common zeolites, which has been exhibited excellent catalytic activities. ${ }^{12-17}$

VOCs are usually emitted in mixture to nature; however, there are few articles about their treatment under this form. The different studies agree on the fact that VOC catalytic oxidation in mixture differs from its simple oxidation. ${ }^{18-21}$

Modeling of chemical processes is an appropriate tool and easy method for investigating of reaction and predicting of variable effect on process. Artificial neural networks (ANNs) are now commonly used in many areas of chemistry and they represent a set of methods that may be useful in solving such problems. $^{22}$ One of the characteristics of modeling based on artificial neural networks is that it does not require the mathematical description of the phenomena involved in the process, and might therefore prove usefulness in simulating and up-scaling catalytic oxidation systems.

In this work, catalytic oxidation of ethyl acetate and toluene (common VOCs with different natures) are studied over NaZSM-5, HZSM-5, Co-ZSM-5 catalysts. Properties of the catalysts are characterized by XRD, EDX, BET, XPS, SEM, TEM and ICP-AES techniques. The influences of parameters such as inlet concentration of organic compounds, reaction temperature, amount of cobalt loading, presence of water vapor as co-feed in inlet feed and effect of mixing of VOCs on the oxidation efficiency are studied. Furthermore, the catalytic oxidation of ethyl acetate on Co-ZSM-5 catalysts is modeled by artificial neural network, and the predicted (calculated) results are compared with experimental results and performance of $\mathrm{ANN}$ is also evaluated. 


\section{Experimental}

Catalyst preparation. Nanostructure Na-ZSM-5 (parent zeolite) was supplied by Iranian industry of petroleum research center. It was a zeolite with a $\mathrm{SiO}_{2} / \mathrm{Al}_{2} \mathrm{O}_{3}$ ratio of 12 , BET surface area of $313 \mathrm{~m}^{2} / \mathrm{g}$ and pore volume of $0.16 \mathrm{~cm}^{3} / \mathrm{g}$. The samples in the $\mathrm{NH}_{4}$-form were prepared by ion-exchange with a $1 \mathrm{M}$ $\mathrm{NH}_{4} \mathrm{NO}_{3}$ (Merck) solution at $70{ }^{\circ} \mathrm{C}$ for $12 \mathrm{~h}$, according to the procedure outlined in the literature. ${ }^{23,24} \mathrm{H}-\mathrm{ZSM}-5$ was obtained after calcinations of $\mathrm{NH}_{4}$-zeolites in air at $450{ }^{\circ} \mathrm{C}$ for $4 \mathrm{~h}$.

Co-ZSM-5 catalysts were prepared by impregnation the HZSM- 5 in $0.2 \mathrm{M}$ of aqueous cobalt acetate (Merck) solution, under different stirring times $(24,12$ and $6 \mathrm{~h})$. Then they were filtered by centrifuging and were dried at $120^{\circ} \mathrm{C}$ for $6 \mathrm{~h}$ followed the calcinations in the furnace with the air stream of $450{ }^{\circ} \mathrm{C}$ for $4 \mathrm{~h}$.

Catalyst characterization. ICP-AES spectroscopy (Integra XL by GBC Australia) was used for determination amount of cobalt in exchanged catalysts. Determination the BET surface area of catalysts was carried out using Micrometrics (Gemini 2375) instrument.

X-ray diffraction (XRD) studies were carried out on a Siemens D500 diffractometer, working with the K $\alpha$ line of copper $(\mathrm{k}=0.154 \mathrm{~nm})$. Measurements of the samples were carried out in the range $2 \theta$ of $0-70^{\circ}$, at a scanning rate of $1 \% \mathrm{~min}$. SEM characterization were carried out with scanning electron microscopy (model EQ-C1-1). Besides, TEM was applied to determine the crystal size of zeolite, which was carried out with Philips CM 200 FEG instrument.

Catalytic activities measurements were carried out in a Shimadzu 2010 gas chromatograph apparatus with a flame inductivity detector (FID). A loading of $0.2 \mathrm{~g}$ of each catalyst in powder form was placed into a U-shaped glass reactor, with length of $30 \mathrm{~cm}$ and inside diameter of $8 \mathrm{~mm}$ (o.d. $11 \mathrm{~mm}$ ). Packing of the catalyst was accomplished with mechanical vibration, and the two ends of the column were plugged with glass wool.

Nitrogen was used as carrier gas, and flow rates were measured using a calibrated soap bubble flow meter. In order to meet the requirement of adsorption at infinite dilution, corresponding to zero coverage and GC linearity, ${ }^{23}$ injected amounts were about $1 \mu \mathrm{L}$. Air was used as a marker for the retention time correction, and it was used to ensure the absence of dead volume when a new column is placed in the chromatograph.

Evaluation of catalytic performance. Catalytic studies were carried out at atmospheric pressure and different temperatures in an electrical furnace controlled by a proportional-integralderivative controller (PID). Catalyst ( $0.2 \mathrm{~g}$ ) was placed over a plug of glass wool and a thermocouple was placed inside the catalyst bed. Before starting each run, catalysts were pre-treated

Table 1. BET results of catalysts

\begin{tabular}{lc}
\hline \multicolumn{1}{c}{ Catalyst } & BET $\left(\mathrm{m}^{2} / \mathrm{g}\right)$ \\
\hline Na-ZSM-5 & 313 \\
Co-ZSM-5 $(0.75 \mathrm{wt} \%)$ & 301 \\
Co-ZSM-5 $(1.5 \mathrm{wt} \%)$ & 282 \\
Co-ZSM-5 (2.8 wt \%) & 271 \\
\hline
\end{tabular}

with $10 \mathrm{~mL} / \mathrm{min}$ of pure nitrogen at $400{ }^{\circ} \mathrm{C}$ in order to eliminate the possible compounds adsorbed on the catalyst surface. After this pretreatment, the reactor was cooled to $100^{\circ} \mathrm{C}$, and the reaction vapor was introduced by passing the carrier gas (nitrogen) flow through a saturator containing the liquid organic compound (ethyl acetate and toluene) and other air stream were used to maintain the molar concentration of organic compound is about $0.2 \%$ in the full stream. Gas flows is controlled by needle valve (Parker Company). All experimental runs were taken under steady state conditions.

\section{Results and Discussion}

\section{Characterization of catalysts.}

Elemental and BET characterization: The elemental composition of the ZSM-5 zeolite was determined by EDX, ICPAES and XPS techniques. All techniques indicated that $\mathrm{Si} / \mathrm{Al}$ ratio for ZSM-5 is approximately 12. Result of BET surface area determination indicated that introduction of cobalt ions onto ZSM-5 caused to decrease of surface area of catalysts. The BET surface areas are listed in Table 1. Compared to the Na-ZSM-5 catalyst, the surface areas decreased after impregnation with Co. The decrease in surface area corresponds to filling of pores of the support.

XRD characterization: The comparison of XRD patterns of the parent ZSM-5 and Co-ZSM-5 catalysts revealed that CoZSM-5 catalysts show no distinguished line attributable neither to oxide phases nor to metal oxide. It is worth mentioning that, in the case of Co-ZSM-5 catalysts, the intensity of peaks were slightly decreased, indicating that mentioned materials have much stable and highly ordered micro pore structures. Besides the mean particle size of catalysts was estimated by Scherer equation, which was estimated about $20-30 \mathrm{~nm}$.

Furthermore, XRD patterns were used to calculate the relative crystallinity of catalysts based on comparing the average intensities of the most intense peaks for the parent versus treated zeolite catalyst. The starting ZSM-5 was assumed to be $100 \%$ crystalline. Table 2 shows the result of XRD pattern for catalysts with different Co loading. It is observed that the Co-ZSM-5 catalysts are less crystalline than parent catalyst and the relative crystallinity is decreased with increasing of Co loading.

Scanning electron microscopy: The scanning electron micrographs of both parent ZSM-5 and Co-ZSM-5 (2.8 wt \%) are shown in Figure1. The comparison of photos 1.a and 1.b indicate that there is not considerable difference between these photos showing that the morphology of catalyst has not obviously changed when cobalt was loaded. SEM images approved the nanostructure of catalysts $(<100 \mathrm{~nm})$, predicted by Scherer formula. Combining the SEM with XRD results we can suggest that
Table 2. Results of XRD pattern for Co-ZSM-5

\begin{tabular}{cccl}
\hline Catalyst & $\mathrm{I}_{\text {CozSM-5 }} / \mathrm{I}_{\text {ZSM-5 }}$ & $\begin{array}{c}\text { Relative } \\
\text { crystallinity(\%) }\end{array}$ & $\mathrm{d}_{\text {Co }} / \mathrm{d}_{\text {ZSM-5 }}$ \\
\hline Co-ZSM-5 (0.75 wt \%) & 0.89 & 89 & $\approx 1$ \\
Co-ZSM-5 (1.5 wt \%) & 0.86 & 86 & $\approx 1.001$ \\
Co-ZSM-5 (2.8 wt \%) & 0.82 & 0.82 & $\approx 1.002$ \\
\hline
\end{tabular}



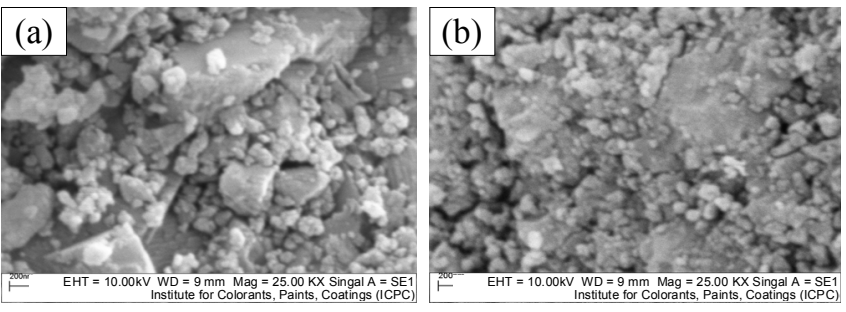

Figure 1. SEM images of (a): parent ZSM-5 and (b): Co-ZSM-5 (2.8 wt \%).
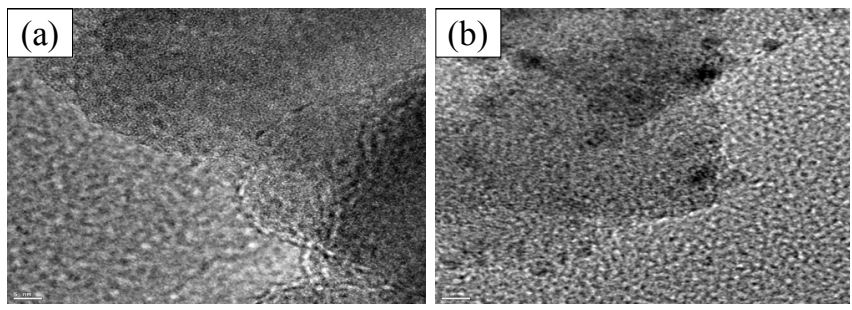

Figure 2. TEM images of (a): parent ZSM-5 and (b): Co-ZSM-5 (2.8 wt \%).

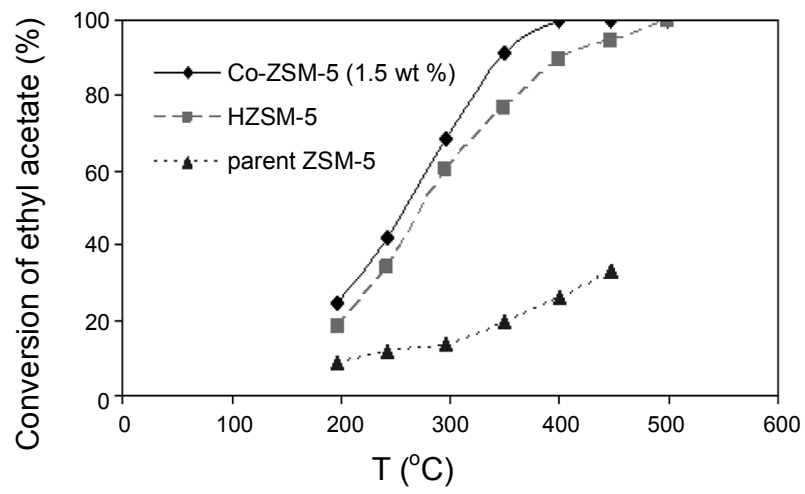

Figure 3. Light-off curve for conversion of ethyl acetate on parent ZSM-5, HZSM-5 and Co-ZSM-5 (1.5 wt \%).

most of Co phase have been well-distributed in ZSM-5 zeolite.

TEM characterization: As regard, the crystal particle size was estimated by Scherer formula and determined by SEM images. To approve the nanostructure of the zeolite used in the catalysts, the TEM images of parent ZSM-5 and Co-ZSM-5(2.8 wt \%) were taken in the scale of $5 \mathrm{~nm}$. TEM images confirmed the nanostructure of catalyst. The images of ZSM-5 zeolite are depicted in Figure 2. Comparison of Figures 2(a) and 2(b) shows that there are some black spots in TEM image of Co-ZSM-5 (2.8\%) which is ascribed to cobalt phase.

Catalytic studies. To study the catalytic activities of catalysts, conversion of toluene and ethyl acetate (inlet concentration of 2000 ppmv) over parent ZSM-5, HZSM-5 and Co-ZSM-5(1.5 wt \%) have been investigated. The related Light-off curves for conversion of ethyl acetate and toluene are shown in Figures 3 and 4 respectively. It is observed that the conversion of both mentioned organic compounds on Co-ZSM-5 is more than that of them on parent ZSM-5 and HZSM-5 catalysts. In other word, catalytic activity of Co-ZSM-5 is higher than HZSM-5, revealing that cobalt plays an important catalytic role in conversion of

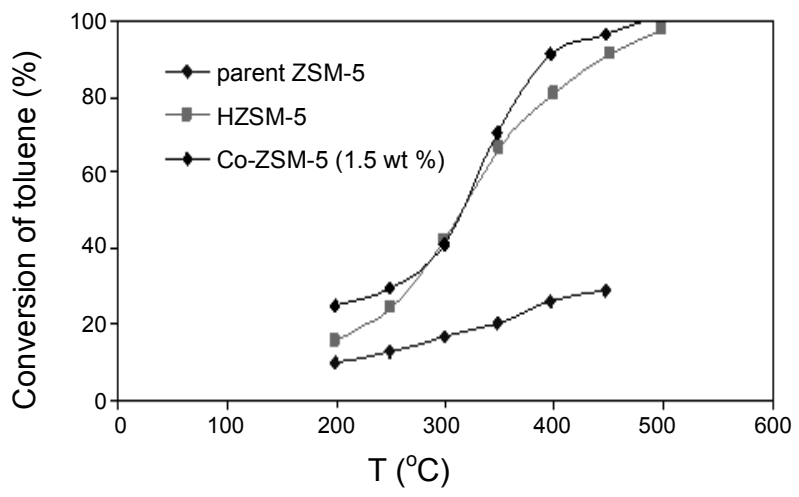

Figure 4. Conversion of toluene over different catalysts.

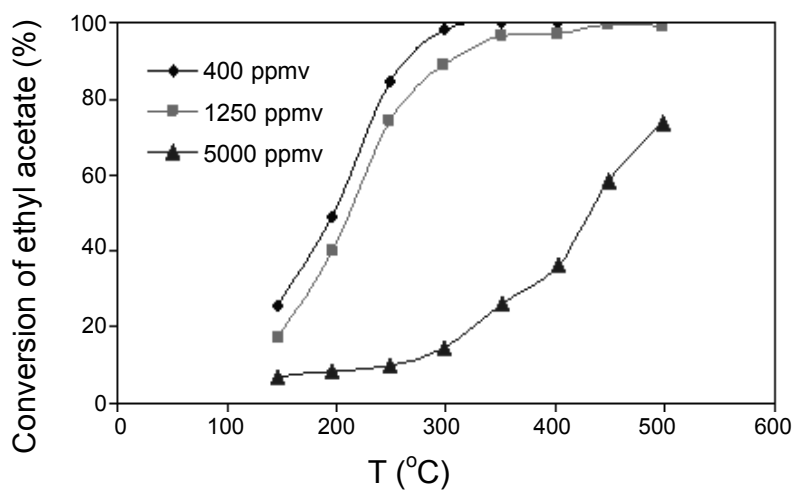

Figure 5. Conversion of ethyl acetate with different inlet concentration.

organic compounds. Furthermore, the GC analysis showed that during conversion of ethyl acetate over parent ZSM-5 and HZSM-5, the larger amount of by-product (mostly aldehydes specially acetaldehyde for ethyl acetate) was detected, which was not shown in this paper. In addition, in comparison to toluene, ethyl acetate is more reactive over Co-ZSM- 5 catalyst. The higher reactivity of ethyl acetate was ascribed to its oxygencontaining group, a well-known electron withdrawing group. Since the oxygen atom in ethyl acetate has an unpaired electron, it could easily interact with the vacant $\mathrm{p}$-orbital of cobalt ion in ZSM-5 catalyst leading to the breakage of the C-O bond in the molecule. Meanwhile, toluene was less reactive due to the occurrence of a resonance effect in its ring.

Effect of inlet concentration of VOC on conversion efficiency: In order to investigate effect of organic compound concentration in inlet feed on catalytic conversion efficiency, gaseous feed containing ethyl acetate with concentrations of 400 , 1250 and 5000 ppm were obtained and their catalytic conversions over Co-ZSM-5 (1.5 wt \%) were studied. The results of this study are shown in Figure 5. It can be observed that, the conversion of ethyl acetate decreases when inlet concentration of ethyl acetate increased and the difference of conversion is more at temperatures between $250-400{ }^{\circ} \mathrm{C}$. At temperature above 400 ${ }^{\circ} \mathrm{C}$, the inlet concentration of VOCs does not show considerable effect on the conversion. This is ascribed to this fact that at low concentration the ratio of deposited molecules on catalyst sites to total molecules in gas phase are higher and consequently the conversion increases. 


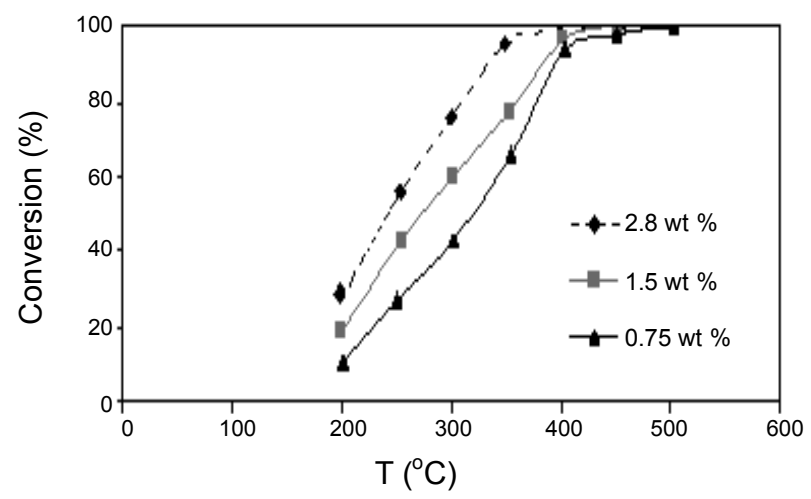

Figure 6. Conversion of ethyl acetate on Co-ZSM-5 with different Co loading.

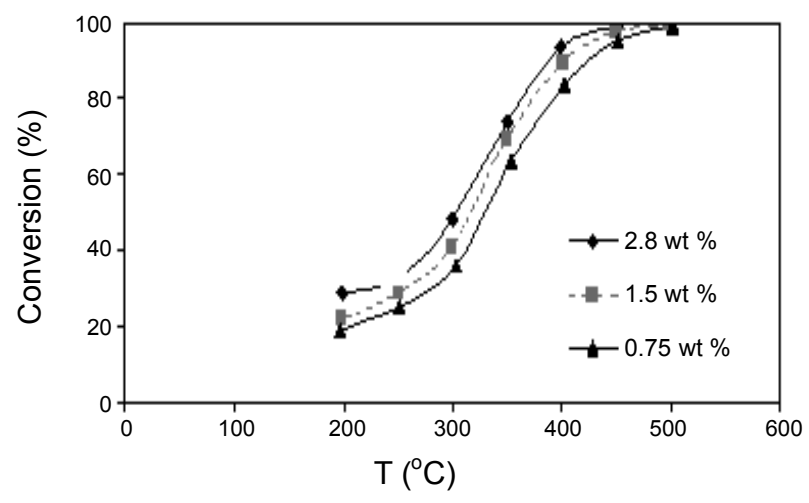

Figure 7. Conversion of toluene on different Co loading of Co-ZSM-5.

Catalytic activity of catalysts with different Co loadings: To make further investigation, catalytic conversions of ethyl acetate and toluene (inlet concentration of $2000 \mathrm{ppmv}$ ) over a series of Co-ZSM-5 catalysts with different Co loadings were studied. Their catalytic activities are compared in Figures 6 and 7 respectively. In the case of ethyl acetate, at below $400{ }^{\circ} \mathrm{C}$, an enhancement of catalytic activity was observed with increasing of the Co loading. A similar trend was found for toluene below $450{ }^{\circ} \mathrm{C}$. At temperatures above these ranges, the amount of cobalt loading did not significantly affect the conversion of organic compounds. Considering these results, it can be confirmed that Co ions play a catalytic role in conversion of organic compounds on Co-ZSM-5 catalyst.

Effect of water vapor as co-feed on conversion of organic compounds: Water vapor is commonly found in air accompanied by other organic compounds. Therefore, the influence of water vapor as co-feed on conversion of ethyl acetate and toluene was studied. It was also resulted that the presence of water vapor as co-feed negatively affects the conversion of ethyl acetate and toluene as shown in Figures 8 and 9 respectively.

The effect of water vapor was also temperature-dependent as the reduction in conversion decreased with an increase in reaction temperature. The inhibitive effect of water on VOC conversion was ascribed to competitive adsorption between these two types of substance.

The interaction of sorbate molecules (VOC and water) with sorbent (Co-ZSM-5) could be in the form of both Van der Waals

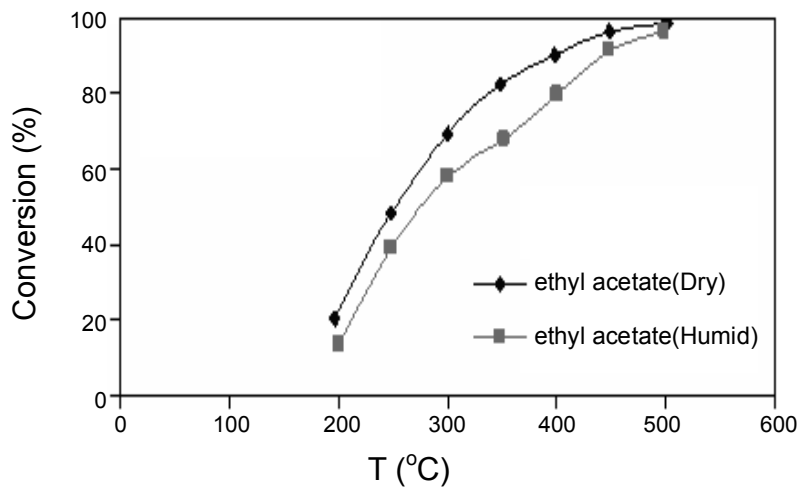

Figure 8. Conversion of ethyl acetate under dry and humid conditions.

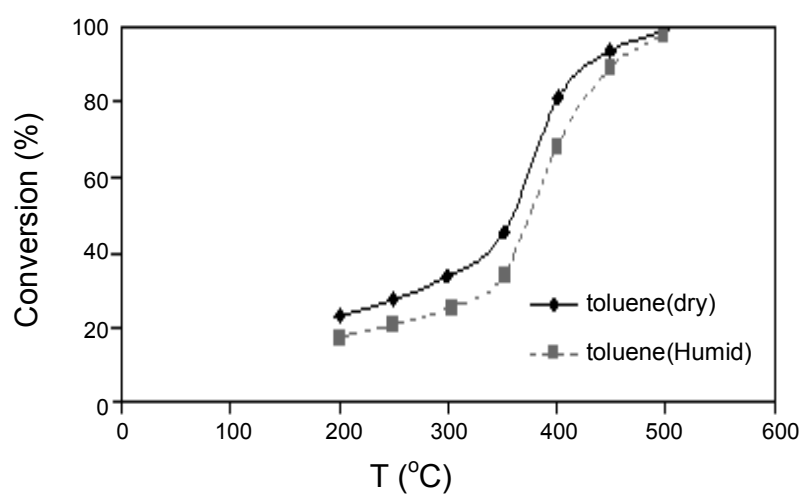

Figure 9. Conversion of toluene under dry and humid conditions.

forces and electrostatic forces. The magnitude of the forces depends on the polar nature of the sorbate and the sorbent. On polar surfaces, such as cation-exchanged zeolites, electrostatic forces dominate Van der Waals force. ${ }^{25}$ Since water is a polar molecule, its adsorption is favored more likely leading to blockage of cationic sites or solvation of nucleophile and, hence, the oxidation of the organic compound is diminised. ${ }^{26}$ Water molecules also have a cluster-forming ability around active sites, thereby creating a diffusion block for VOC molecules. At higher temperatures, this localization might be prevented and consequently the deactivation effect of water molecules diminishes as observed in Figures 8 and 9.

Conversion of organic compounds in a binary mixture: The catalytic combustion of ethyl acetate and toluene in a binary mixture was studied over Co-ZSM-5 (1.5 wt \%). Figure 10 shows the promotional and inhibition behavior between ethyl acetate and toluene in a binary mixture. The conversion of ethyl acetate was improved while that of toluene droped when presented together. These behaviors are ascribed to competitive adsorption of organic compounds on the catalyst sites as the main reason for the promotion-inhibition effect in binary VOC mixtures. $^{25}$

Neural network modeling. In order to study and to obtain a black box model we modeled the oxidation of ethyl acetate using artificial neural network. ANNs are direct inspiration from the biology of human brain, where billions of neurons are interconnected to process variety of complex information. Accor- 


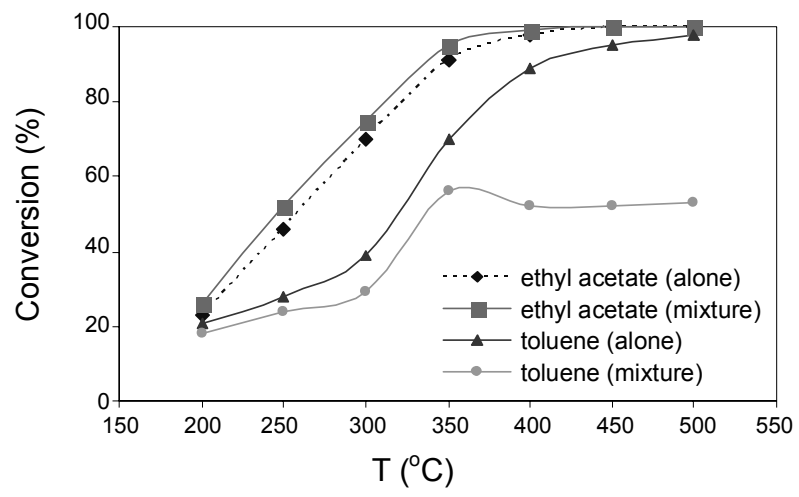

Figure 10. Conversion of toluene and ethyl acetate under mixture condition.

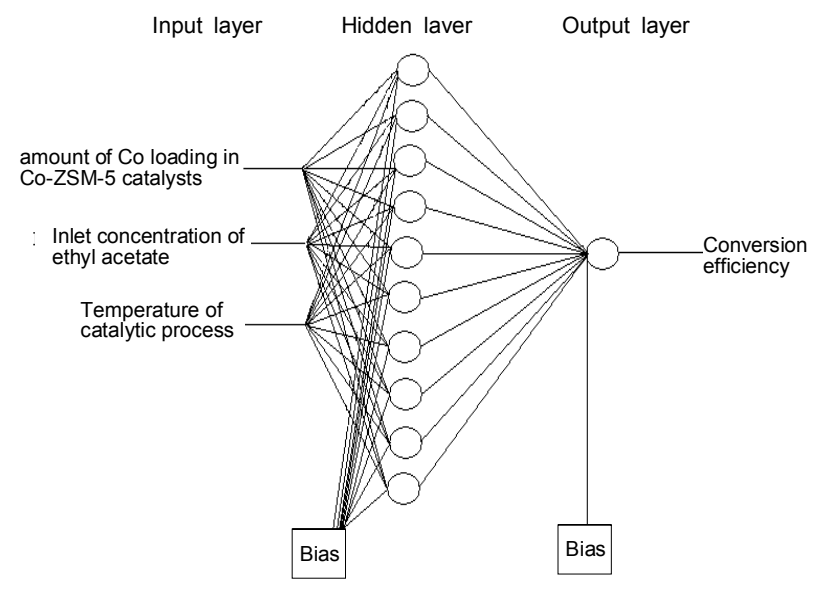

Figure 11. The ANN optimized structure.

dingly, a computational neural network consists of simple processing units called neurons.

A neural net is parallel interconnected structure consisting of: (1) input layer of neuron (independent variables), (2) a number of hidden layers and (3) output layer (dependent variables). The number of input and output neurons is determined by the nature of the problem. Hidden layers act like feature detectors and theoretically existence of more than one hidden layer is possible. However, universal approximation theory suggests that a network with a single hidden layer with a sufficiently large number of neurons can interpret any input-output structure. ${ }^{22}$

Topology of an artificial neural network is determined by number of its layers, number of nodes in each layer and the nature of transfer functions. Optimization of ANN topology is probably the most important step in development of model.

We used three-layered feed forward back propagation neural network (3-10-1) for modeling of ethyl acetate oxidation on Co-ZSM-5 catalysts (Figure 11). In the present work, input variables to the feed forward neural network were as follows: inlet concentration of VOC, amount of cobalt loading in Co-ZSM-5 catalysts, and reaction temperature $\left({ }^{\circ} \mathrm{C}\right)$. Conversion efficiency of ethyl acetate was chosen as the experimental response or output variable. In order to determine the optimum number of hidden nodes, a series of topologies was used, in which the number of nodes were varied from 7 to 17 . Each topology was repeated

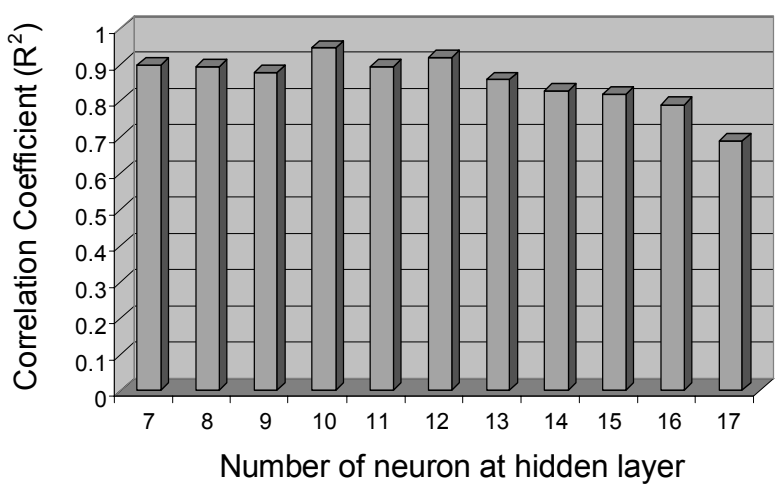

Figure 12. The correlation coefficient values for predicted and experimental test data versus number of neurons in hidden layer.

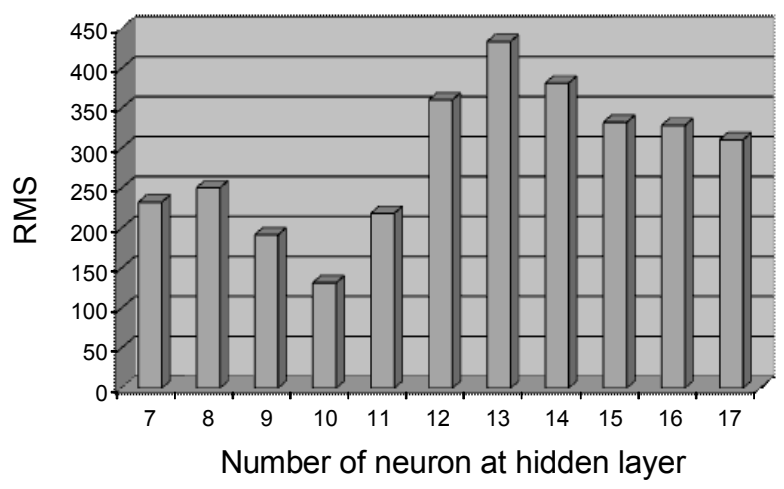

Figure 13. RMS values for predicted and experimental test data versus number of neurons in hidden layer.

three times to avoid random correlation due to random initialization of the weights. The mean square error (MSE) was used as the error function. ${ }^{22}$

The training function was TRAINLM (Liebenberg Marquart function). Out of the several data points generated, 64 experimental sets were used to feed the ANN structure. The samples were divided into training, validation and test subsets that each of them contains 39, 12 and 13 samples, respectively. The validation and test sets, for evaluation of the validation and modeling power of the model, were randomly selected from the experimental data. The used transfer function in the hidden layer was Tan- sigmoid and purelin was selected for output layer. All samples must be scaled into the -0.9 to 0.9 . So any samples $\left(X_{i}\right)$ (from the training, validation and test sets) were scaled to a new value $A_{i}$ as follows:

$$
A_{i}=\left(\frac{X_{i}-\min \left(X_{i}\right)}{\max \left(X_{i}\right)-\min \left(X_{i}\right)}\right)\left(r_{\max }-r_{\min }\right)+r_{\min }
$$

Where $\min \left(X_{i}\right)$ and $\max \left(X_{i}\right)$ are extreme values of variable $X_{i}$. Of course to calculate training, validation and test errors, all outputs were performed an inverse range scaling to return the predicted responses to their original scale then they were compared with experimental responses. The modeling was carried 
Table 3. Matrix of weights; weights between input and hidden layers $\left(\mathrm{W}_{1}\right)$; weights between hidden and output layers $\left(\mathrm{W}_{2}\right)$.

\begin{tabular}{|c|c|c|c|c|c|c|c|}
\hline \multicolumn{5}{|c|}{$\mathrm{W}_{1}$} & \multicolumn{3}{|c|}{$\mathrm{W}_{2}$} \\
\hline \multirow{2}{*}{ Neurons No } & \multicolumn{3}{|c|}{ Weights of variables } & \multirow{2}{*}{ Bias } & \multirow{2}{*}{ Neurons No } & \multirow{2}{*}{ Weights of variables } & \multirow{2}{*}{ Bias } \\
\hline & Co loading & Inlet VOC's concentration & Temperature & & & & \\
\hline 1 & 1.0884 & 1.2751 & 2.5143 & -0.071 & 1 & -3.8353 & -0.1769 \\
\hline 2 & -1.1407 & 2.6811 & 1.0679 & 0.59146 & 2 & 1.6144 & \\
\hline 3 & -1.8898 & -2.0356 & 1.951 & 0.02209 & 3 & -1.5193 & \\
\hline 4 & 2.5804 & 1.9163 & -3.1884 & -0.1452 & 4 & 0.46594 & \\
\hline 5 & -0.5587 & -0.0313 & -2.1907 & -0.1201 & 5 & -1.2525 & \\
\hline 6 & -3.1858 & -1.6551 & 3.4746 & 0.41367 & 6 & -0.26 & \\
\hline 7 & 1.274 & -2.7417 & 2.3294 & -0.4737 & 7 & 0.71652 & \\
\hline 8 & 1.8088 & 2.6145 & -1.6624 & -0.8372 & 8 & -1.7156 & \\
\hline 9 & -1.5536 & 2.306 & -0.7292 & 1.0514 & 9 & -2.5704 & \\
\hline 10 & -0.5427 & 2.9991 & 0.02785 & 0.54714 & 10 & 3.0484 & \\
\hline
\end{tabular}

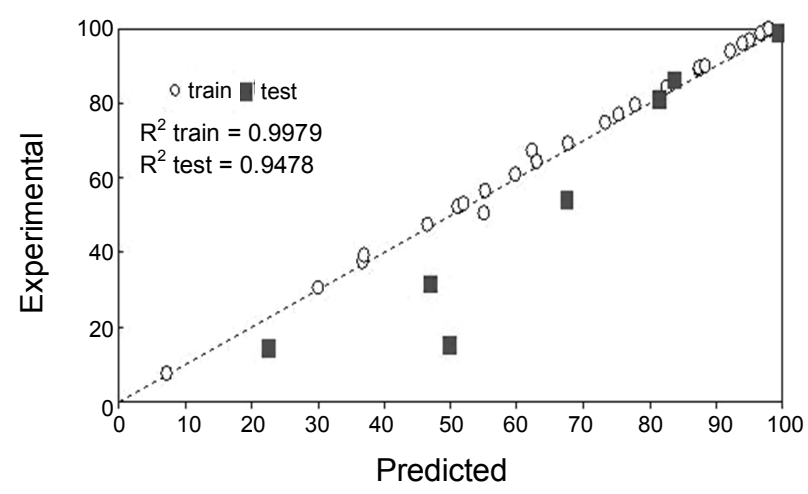

Figure 14. Comparison of the experimental results with those calculated via neural network modeling for the test and train sets.

out for different neurons in hidden layer and one neuron at output layer. The predicted results for test series denormalized and compared with experimental test series and the correlation coefficient $\left(\mathrm{R}^{2}\right)$ and RMS were calculated for all of them. The results of correlation coefficient and RMS versus number of neurons at hidden layer are shown in Figures 12 and 13 respectively. As can be seen from Figure 12, for a hidden layer with 10 neurons, the $\mathrm{R}^{2}$ has the highest value and also the mean square error (RMS) is the minimum just about 10 neurons (Figure 13). The ANN used in this work (10 neurons in hidden layer) provided the weights listed in Table 3 . The weights are coefficients between the artificial neurons, which are analogous to synapse strengths between the axons and dendrites in real biological neurons. Therefore, 10 neurons in hidden layer was each weight decides what proportion of the incoming signal will be transmitted into the neuron's body. ${ }^{22}$

The results predicted by ANN model and experimental values of the output variable (conversion) for both train and test sets are present in Figure 14. Plots in this Figure have correlation coefficient of 0.9979 for train set and 0.9478 for test set. Results confirm that neural network model reproduces the conversion in this system, within experimental ranges adopted in the fitting model. Another application of ANN modeling is to determine the importance of each input variable on output variable i.e. conversion efficiency of ethyl acetate. In order to assess the relative importance of the various input variables on the output variable, it was proposed an equation based on the partitioning of connection weights:

$$
I_{j}=\frac{\sum_{m=1}^{m=N_{h}}\left(\left(\left|W_{j m}^{j h}\right| / \sum_{k=1}^{N_{i}}\left|W_{k m}^{i h}\right|\right) \times\left|W_{m n}^{h o}\right|\right)}{\sum_{k=1}^{k=N_{i}}\left\{\sum_{m=1}^{m=N_{h}}\left(\left|W_{j m}^{j h}\right| / \sum_{k=1}^{N_{i}}\left|W_{k m}^{i h}\right|\right) \times\left|W_{m n}^{h o}\right|\right\}}
$$

where $I_{j}$ is the relative importance of the jth input variable on the output variable, $N_{i}$ and $N_{h}$ are the numbers of input and hidden neurons, respectively, $W_{\mathrm{s}}$ are connection weights, the superscripts ' $i$ ', ' $h$ ' and ' $o$ ' refer to input, hidden and output layers, respectively, and subscripts ' $k$ ', ' $m$ ' and ' $n$ ' refer to input, hidden and output neurons, respectively. ANN model predicted that the reaction temperature on conversion of ethyl acetate is more important than those of Co loading and inlet concentration of ethyl acetate, in which the importance of variables were determined 50\%, 24.915 and 25.085 respectively.

\section{Conclusions}

This study revealed the catalytic role of transition metal onto zeolites and high performance of Co-ZSM-5 nano catalyst. The present study in agreement with other studies shows that the nanostructure catalysts show higher activity than other catalysts because of having higher specific surface area. The study revealed that for medium pore zeolites such as ZSM-5, the effect shape selectivity could not be totally ruled out as the relatively linear ethyl acetate molecule enabled it to diffuse much easier along the channel of the zeolites. The competitive adsorption is the main reason for the promotion-inhibition effect in binary VOC mixtures. Water vapor is an inhibitive factor in conversion of organic compounds over zeolite based catalysts. Artificial neural network modeling has been successfully used to investigate the cause effect relationship in catalytic oxidation process. The ANN model makes it possible to predict how much each variable affects on the conversion efficiency. 
Acknowledgments. The authors are thankful to those who contributed to enhancing of this project especially Iranian Nanotechnology Initiative and center of excellence for new material and clean chemistry of Tabriz university for their encouragement support and also Mr. Pejman Hojjati from Monash university, Australia and Mr. Bahrami from Tabriz university for BET surface area and XRD analysis respectively.

\section{References}

1. Mukhopadhyay, N.; Moretti, E. AIChE, New York, 1993, 20.

2. Yang, Y.; Xu, X.; Sun, K. Catal. Commun. 2006 7, 756.

3. Lin, P. Y.; Skoglundh, M.; Löwendahl, L.; Otterstédt, J. E.; Dahl, L.; Jansson, K.; Nygren, M. Appl. Catal. B 1995, 6, 237.

4. Law, T.; Chao, C.; Chan,Y.; Law, A. Atmos. Environ. 2003, 37, 5433.

5. Li, W.; Zhuang, M.; Hua, J. Catal. Today 2004, 93, 205.

6. Wang, C. H. Chemosphere 2004, 55, 11

7. Yang, Y.; Xu, X.; Sun, K. J. Hazard. Mater. B 2007, 139, 140.

8. Headon, K.; Zhang, D. K. Ind. Eng. Chem. Res. 1997, 36, 4595.

9. Corma, A.; Navarro, M. T. Stud. Surf. Sci. Catal. 2002, 142, 487.

10. Chatterjee, S.; Greene, H. L.; Park, Y. J. J. Catal. 1992, 138, 179.

11. Ribeiro, M. F.; Silva, J. M.; Brimaud, S.; Magnoux, P.; Murphy, D. M. Appl. Catal. B 2007, 70, 384.
12. Kharas, K.; Liu, D.; Robota, H. Catal. Today 1995, 26, 129.

13. Nicolaides, C.; Sincadu, N.; Scurrell, M. S. Stud. Surf. Sci. Catal. 2001, 136, 333.

14. Liu, C.; Deng, Y.; Pan, Y.; Gu, Y.J. Mol. Catal. A 2004, 215, 195.

15. Yamanaka, H.; Hamada, R.; Nibuta, H. J. Mol. Catal. A 2002, 178, 89.

16. Wong, C.; Abdullah, A.; Bhatia, S. J. Hazard. Mater. 2008, 157, 480

17. Stöcker, M. Micropor. Mesopor. Mater. 2005, 82, 257.

18. Tsou, J.; Magnoux, P.; Guisnet, M.; Órfão, J.; Figueiredo, J. L. Appl. Catal. B 2005, 57, 117.

19. Burgos, N.; Paulis, M.; Mirari Antxustegi, M.; Montes, M. Appl. Catal. B 2002, 38, 251.

20. Papaefthimiou, P.; Ioannides, T.; Verykios, X. E. Appl. Catal. B 1998, 15,75 .

21. Fonseca, R.; Ortiz, J. I.; Ayastui, J. L.; Ortiz, M.; Velasco, J. Appl. Catal. B 2003, 45, 13.

22. Salari, D.; Niaei, A.; Khataee, A.; Zarei, M. J. Electroanal. Chem. 2009, 629, 117.

23. Hoefnagel, A. J.; Bekkum, H. V. Catal. Lett. 2003, 85, 7.

24. Kirumakki, S. R.; Nagaraju, N.; Cari, K. J. Catal. 2004, 221, 549.

25. Abdullah, A. Z.; Abuu Bakar, M. Z.; Bhatia, S. Ind. Eng. Chem. Rev. 2003, 42, 6059.

26. Atwood, G. A.; Greene, H. L.; Chintawar, P.; Rachapudi, R.; Ramachandran, B.; Vogel, C. A. Appl. Catal. B 1998, 18, 51. 